\title{
Relationship between abnormal sperm morphology induced by dietary zinc deficiency and lipid composition in testes of growing rats
}

\author{
Krystal J. Merrells, Heather Blewett, Jennifer A. Jamieson, Carla G. Taylor and Miyoung Suh* \\ Department of Human Nutritional Sciences, University of Manitoba, Winnipeg, Manitoba, Canada R3T 2N2
}

(Received 26 August 2008 - Revised 10 October 2008 - Accepted 13 October 2008 - First published online 18 February 2009)

The present study investigated the effect of dietary $\mathrm{Zn}$ deficiency during sexual maturation on sperm integrity and testis phospholipid fatty acid composition. Male weanling Sprague-Dawley rats were randomised into four dietary groups for 3 weeks: $\mathrm{Zn} \mathrm{control} \mathrm{(ZC;} 30 \mathrm{mg} \mathrm{Zn} / \mathrm{kg}$ ); Zn marginally deficient (ZMD; $9 \mathrm{mg} \mathrm{Zn/kg);} \mathrm{Zn} \mathrm{deficient} \mathrm{(ZD;}<1 \mathrm{mg} \mathrm{Zn/kg);} \mathrm{pair} \mathrm{fed} \mathrm{(PF;} 30 \mathrm{mg} \mathrm{Zn/kg)} \mathrm{to} \mathrm{the} \mathrm{ZD} \mathrm{group.} \mathrm{Morphology} \mathrm{of} \mathrm{cauda} \mathrm{epi-}$ didymal sperm and lipid profiles of testis phospholipids were analysed. The rats fed the ZD diet had a lower testis weight $(P<0 \cdot 02)$. Seminal vesicles and prostate weight were also lower in the ZD and PF groups. Rats fed the ZD diet, but not the ZMD diet, had 34-35\% more abnormal spermatozoa and $24 \%$ shorter sperm tail length than the ZC and PF rats $(P<0 \cdot 001)$. Testis cholesterol concentration was higher in the ZD rats compared with the ZC and PF rats $(P<0 \cdot 04)$. Testes were highly enriched with $n-6$ fatty acids by showing $n-6: n-3$ fatty acid ratios of $27: 1$ in phosphatidylcholine (PC) and 23:1 in phosphatidylethanolamine (PE). The dominant fatty acid in testes was docosapentaenoic acid (22:5n-6), comprising 15 and $24 \%$ of PC and PE, respectively. This fatty acid was significantly lower in the ZD rats, whereas $18: 2 n-6$ was higher compared with the rats in the other diet groups. These results demonstrate that severe $\mathrm{Zn}$ deficiency adversely affects sperm integrity and modulates testis fatty acid composition by interrupting essential fatty acid metabolism. This suggests that $\mathrm{Zn}$ deficiency-associated abnormal testicular function is perhaps preceded by altered membrane fatty acid composition, especially of a major fatty acid, 22:5n-6.

Zinc deficiency: Rats: Sperm morphology: Fatty acids: Docosapentaenoic acid: Elongation and desaturation

$\mathrm{Zn}$ is abundant in the male reproductive system. The adult prostate followed by testes have the highest $\mathrm{Zn}$ concentrations of all other organs in the body ${ }^{(1)}$. The role of this element in testicular function is to promote the maturation of testis germinal cells into spermatozoa, and $\mathrm{Zn}$ is believed to prolong the life of spermatozoa once released into the external environment $^{(1,2)}$. Zn deficiency induces testicular atrophy, spermatocyte loss, an increase in spermatogenic cell apoptosis and significant decreases in seminiferous tubule diameter ${ }^{(3-5)}$. Adult males who were on a Zn-restricted diet for 24-40 weeks experienced oligospermia ${ }^{(6)}$, defined as a sperm count of less than 20 million per ml ejaculate in humans. It is therefore evident that $\mathrm{Zn}$ is an essential element in male fertility.

Male reproductive organs have a unique biomembrane lipid composition, especially in the testes and sperm. Mammalian testes and spermatozoa are enriched in long-chain PUFA of up to twenty-two carbons ${ }^{(7,8)}$. In the testes, up to $65 \%$ of long-chain PUFA are composed of 20:4n-6 (arachidonic acid), $22: 5 n-6$ (docosapentaenoic acid) and $22: 6 n-3$ (DHA). In rat testes and spermatozoa, $22: 5 n-6$ is the dominant long-chain PUFA, whereas in humans it is $22: 6 n-3^{(8)}$. Both have similar roles, increasing in concentration in testis germinal cells during the later stages of their maturation into spermatozoa $^{(7,8)}$. When the level of testis long-chain PUFA is altered, spermatogenesis is impaired, and this is observed in all mammals ${ }^{(7)}$. This suggests that in addition to $\mathrm{Zn}$, longchain PUFA are also important for proper sperm production and testis function.

Long-chain PUFA in the tissues and organs of the body are derived from dietary essential fatty acids, $18: 2 n-6$ (linoleic acid) and 18:3n-3 ( $\alpha$-linolenic acid) by elongation and desaturation systems. Since $\mathrm{Zn}$ plays a role in the desaturation of $n-3$ and n-6 long-chain PUFA ${ }^{(9)}$, a deficiency of Zn may influence the long-chain PUFA content and composition, thereby affecting overall testicular function. Animals on $\mathrm{Zn}$-deficient diets for more than 6 weeks have shown decreased activity of $\Delta 5$ and $\Delta 6$ desaturases in the testes ${ }^{(10-12)}$. This condition may affect $22: 5 n-6$, the dominant long-chain PUFA in rat testes. Thus, the present study investigates the effects of severe and marginal $\mathrm{Zn}$ deficiency during sexual maturation on the level and composition of long-chain PUFA in testes as well as sperm morphology during sexual maturation.

\section{Materials and methods}

Animals and diets

Male weanling Sprague-Dawley rats, aged 3 weeks (Charles River Laboratories, St Constant, PQ, Canada), were acclimatised for $5 \mathrm{~d}$ to a controlled environment of $21-23^{\circ} \mathrm{C}, 55 \%$ 
humidity and $14 \mathrm{~h}$ light $-10 \mathrm{~h}$ dark cycles while being fed the control diet. The rats were then randomised into four dietary groups with a varied $\mathrm{Zn}$ level: $\mathrm{Zn}$ control (ZC; $30 \mathrm{mg} \mathrm{Zn/}$ $\mathrm{kg}$ ), Zn marginally deficient (ZMD; $9 \mathrm{mg} \mathrm{Zn/kg),} \mathrm{Zn} \mathrm{deficient}$ (ZD; $<1 \mathrm{mg} \mathrm{Zn/kg),} \mathrm{or} \mathrm{pair} \mathrm{fed} \mathrm{to} \mathrm{the} \mathrm{ZD} \mathrm{group} \mathrm{(PF;} 30 \mathrm{mg}$ $\mathrm{Zn} / \mathrm{kg}$ ). Since $\mathrm{Zn}$ deficiency can induce anorexia within $3 \mathrm{~d}$, $\mathrm{PF}$ rats were fed the same nutritionally complete diet as the $\mathrm{ZC}$ rats; however, each $\mathrm{PF}$ rat received only the amount of feed as consumed on the previous day by the individual ZD rat paired to it. The PF group controls for the effects of undernutrition commonly seen in Zn deficiency. Basal experimental diets were semi-synthetic, nutritionally complete diets based on AIN-93G with slight modifications ${ }^{(13)}$. The composition (per kg diet) was as follows: dextrose, 594.6 g; egg albumin, $212.5 \mathrm{~g}$; cellulose, $50 \mathrm{~g}$; mineral mix, $35 \mathrm{~g}$ (AIN-93M, Zn free); vitamin mix, $10 \mathrm{~g}$ (AIN-93); soyabean oil, $70 \mathrm{~g}$; biotin premix, $10 \mathrm{~g}$ (contained $200 \mathrm{mg}$ biotin/kg); potassium phosphate, $5.4 \mathrm{~g}$; choline, $2.5 \mathrm{~g}$. $\mathrm{Zn}$ in the premix was added as $\mathrm{ZnCO}_{3}$ in the necessary concentrations for each diet group. With the exception of the PF group, animals were allowed access to food and water ad libitum. After a 3-week feeding period, animals were killed by $\mathrm{CO}_{2}$ asphyxiation and decapitation. Trunk blood was collected to obtain serum. Body weight was recorded, and the epididymis, seminal vesicles and prostate were removed. Excised testes were weighed, immediately frozen in liquid $\mathrm{N}_{2}$, and stored at $-80^{\circ} \mathrm{C}$. Animal care was in accordance with a protocol approved by the University of Manitoba Protocol Management and Review Committee and followed the guidelines of the Canadian Council on Animal Care ${ }^{(14)}$.

\section{Mineral analysis}

$\mathrm{Zn}$ concentration was measured in serum and femurs as described by Hosea et al. ${ }^{(15)}$. Femurs were excised and cleaned of soft tissue. After wet and dry weights were obtained, whole femurs were wet-washed using nitric acid as previously described ${ }^{(15)}$. All glassware was acid-washed to prevent contamination. After appropriate dilution of digests, $\mathrm{Zn}$ concentration was determined in triplicate by atomic absorption spectroscopy (Spectra AA-30 Spectrophotometer; Varian Canada, Georgetown, Canada). Quality control was monitored using bovine liver standard reference material 1577b (US Department of Commerce, National Institute of Standards and Technology, Gaithersburg, MD, USA).

\section{Sperm morphology}

Sperm morphology was measured according to Sprando et al. ${ }^{(16)}$ and the Rat Sperm Morphological Assessment Guideline Document ${ }^{(17)}$. Briefly, the cauda epididymis was removed, weighed and minced in $2 \mathrm{ml}$ of $0.9 \%$ saline solution. After $5 \mathrm{~min}$, a sample of minced epididymis was fixed in $10 \%$ buffered formalin for $5 \mathrm{~min}$ and then further diluted with deionised water. Staining was obtained with $1 \%$ eosine $\mathrm{Y}$ and the sample was smeared onto microscope slides and air-dried. Slides were analysed using a bright field optical microscope at 400X (Carsen, Olympus, Tokyo, Japan). A total of 200 spermatozoa were counted per animal and were divided into four categories based on their morphology: normal, abnormal head, abnormal tail and both abnormal head and tail.
Normal morphology was defined as a hooked head and smooth tail ${ }^{(17)}$. An abnormal head was defined as a missing head, flattened hook (banana) or pinhead. An abnormal tail was characterised with a bent or coiled tail. Sperm tail length was also measured using Image Pro Plus 5.0 computer software (Media Cybernetics Inc., Silver Spring, MD, USA). Measurements were taken by tracing the tail starting from the bottom of the dense nucleus (of the head) down to the tip of the tail.

\section{Lipid and fatty acid analysis}

Testes were decapsulated, weighed and total lipids were extracted using the Folch method ${ }^{(18)}$. Individual phospholipids were separated on silica gel $\mathrm{H}$ plates with a chloroform-methanol-2-propanol-0.25\% KCl (w/v)-triethylamine (30:9:25:6:18, by vol.) developing system. Phospholipids were visualised with $0 \cdot 1 \%$ aniline naphthalene sulfonic acid in water (w/v) under UV light. Fatty acids in individual phospholipids were transformed into fatty acid methyl esters (FAME) by boiling in $1.5 \mathrm{ml} 14 \%$ boron trifluoride in methanol and $2 \mathrm{ml}$ hexane. FAME were analysed by GC using a GC-17A Shimadzu gas chromatograph (Mandel Scientific Co. Ltd, Guelph, ON, Canada). An SGE BPX70 capillary column $(30 \mathrm{~m} \times 0.25 \mu \mathrm{m}$ internal diameter $)$ was used ${ }^{(19)} . \mathrm{H}_{2}$ was the carrier gas. The initial temperature was set at $130^{\circ} \mathrm{C}$ and increased to $240^{\circ} \mathrm{C}$ at the rate of $10^{\circ} \mathrm{C} / \mathrm{min}(0 \mathrm{~min}$ holding time $), 1^{\circ} \mathrm{C} / \mathrm{min}$ ( 0 min holding time) and $3^{\circ} \mathrm{C} / \mathrm{min}$ ( $15 \mathrm{~min}$ holding time). All fatty acids were compared with a commercial standard (NuChek Prep 461; Elysian, MN, USA).

\section{Triacylglycerol and cholesterol determination in testes}

TAG and cholesterol levels in testis lipid were determined using commercially available kits (Diagnostic Chemicals Ltd, Charlottetown, PEI, Canada). The DC-CAL SE-035 standard (Diagnostic Chemicals Ltd) was used for both assays. The analysis was performed by the protocol provided with the kit with samples dissolved in 2-propanol ${ }^{(20)}$.

\section{Statistical analysis}

The effect of $\mathrm{Zn}$ treatment on sperm morphology, fatty acid composition and lipids (TAG, cholesterol) were tested by oneway ANOVA using the SAS Statistical package (version 9.0; SAS Institute, Inc., Cary, NC, USA). A probability of $P \leq 0.05$ was considered significant. Significant differences between diet treatments were determined by Duncan's multiple range test $^{(21)}$. All data are expressed as mean values and standard deviations. For data representing $n 2$ in Table 3, trend analysis $\left(R^{2}\right)$ was performed on the two independent datasets.

\section{Results}

\section{Body and organ weights and zinc status}

There were significant differences in body and sex-organ weights among groups. The final body weight of the ZD rats was the lowest followed by the PF rats (53 and $62 \%$ of $\mathrm{ZC}$ rats, respectively) (Table 1). Organ weights, both absolute (g) and relative organ weights (\% of body weight), are shown in Table 1. The ZD rats, but not the PF rats, had 
Table 1. Body and organ weight $(\mathrm{g})$ and relative weight (\% body weight) in response to dietary zinc treatment (Mean values and standard deviations for four or five rats per group)

\begin{tabular}{|c|c|c|c|c|c|c|c|c|c|}
\hline \multirow[t]{2}{*}{ Zn treatment... } & \multicolumn{2}{|c|}{ ZC } & \multicolumn{2}{|c|}{ ZMD } & \multicolumn{2}{|c|}{ ZD } & \multicolumn{2}{|c|}{$\mathrm{PF}$} & \multirow[b]{2}{*}{$P$} \\
\hline & Mean & SD & Mean & SD & Mean & SD & Mean & SD & \\
\hline Body weight (g) & $263 \cdot 3^{a}$ & $14 \cdot 2$ & $257 \cdot 5^{a}$ & $18 \cdot 2$ & $146 \cdot 1^{\mathrm{c}}$ & $8 \cdot 1$ & $168 \cdot 2^{b}$ & $8 \cdot 2$ & $<0.0001$ \\
\hline \multicolumn{10}{|l|}{ Organ weight (g) } \\
\hline Testes & $2 \cdot 60^{\mathrm{a}}$ & 0.21 & $2 \cdot 55^{a}$ & 0.27 & $2 \cdot 14^{\mathrm{b}}$ & 0.10 & $2 \cdot 46^{\mathrm{a}}$ & 0.11 & 0.0173 \\
\hline Epididymis & 0.40 & 0.06 & 0.41 & 0.08 & 0.28 & 0.05 & 0.34 & 0.06 & NS \\
\hline Prostate & $0.37^{\mathrm{a}}$ & 0.04 & $0.37^{\mathrm{a}}$ & 0.07 & $0 \cdot 18^{\mathrm{b}}$ & 0.06 & $0.19^{b}$ & 0.05 & 0.0002 \\
\hline Seminal vesicles & $0.59^{a}$ & 0.12 & $0.62^{\mathrm{a}}$ & 0.07 & $0.21^{\mathrm{b}}$ & 0.09 & $0.30^{\mathrm{b}}$ & 0.06 & $<0.0001$ \\
\hline \multicolumn{10}{|l|}{ Organ wt (\% body weight) } \\
\hline Testes & $0.99^{\mathrm{b}}$ & 0.05 & $0.99^{\mathrm{b}}$ & $0 \cdot 10$ & $1.48^{\mathrm{a}}$ & 0.08 & $1.47^{\mathrm{a}}$ & $0 \cdot 13$ & $<0.0001$ \\
\hline Epididymis & $0.15^{\mathrm{c}}$ & 0.02 & $0.15^{b, c}$ & 0.03 & $0.19^{a, b}$ & 0.03 & $0.20^{a}$ & 0.03 & 0.0346 \\
\hline Prostate & 0.13 & 0.01 & 0.14 & 0.03 & 0.12 & 0.04 & 0.11 & 0.03 & NS \\
\hline Seminal vesicles & $0.22^{a}$ & 0.05 & $0.23^{a}$ & 0.02 & $0.14^{b}$ & 0.06 & $0.18^{\mathrm{a}, \mathrm{b}}$ & 0.04 & 0.0428 \\
\hline Serum Zn $(\mu \mathrm{mol} / / \mathrm{l})$ & $30 \cdot 6^{\mathrm{a}}$ & 1.8 & $15 \cdot 3^{\mathrm{b}}$ & 4.6 & $4.9^{\mathrm{c}}$ & 0.7 & $26 \cdot 6^{\mathrm{a}}$ & $4 \cdot 0$ & $<0.0001$ \\
\hline Femur Zn ( $\mu \mathrm{mol} / \mathrm{g}$ dry $w t)$ & $4 \cdot 82^{a}$ & 0.20 & $2 \cdot 23^{\mathrm{c}}$ & 0.78 & $1.06^{\mathrm{d}}$ & 0.16 & $3.93^{b}$ & $0 \cdot 11$ & $<0.0001$ \\
\hline
\end{tabular}

ZC, Zn control; ZMD, Zn marginally deficient; ZD, Zn deficient; PF, pair fed.

$\mathrm{a}, \mathrm{b}, \mathrm{c}, \mathrm{d}$ Mean values within a row with unlike superscript letters were significantly different $(P<0.05)$.

significantly $(P<0 \cdot 02)$ smaller testes in comparison with animals fed the ZC and ZMD diets. Seminal vesicle and prostate weights were lower in both the $\mathrm{ZD}$ and $\mathrm{PF}$ rats compared with the $\mathrm{ZC}$ and $\mathrm{ZMD}$ groups $(P<0 \cdot 0002)$. Epididymis weight was lower in the $\mathrm{ZD}$ rats but was not significantly different from the other groups (Table 1). When these organs were calculated as a percentage of body weight, the ZD and PF rats had higher relative testis and epididymis weights in comparison with the $\mathrm{ZC}$ rats. Relative seminal vesicle weight was lowest in the $\mathrm{ZD}$ rats.

Serum and femur $\mathrm{Zn}$ concentrations reflected $\mathrm{Zn}$ treatment (Table 1). The ZD and ZMD rats had 84 and 50\%, respectively, lower serum concentration compared with the $\mathrm{ZC}$ rats. Femur $\mathrm{Zn}$ concentration, an indicator of long-term $\mathrm{Zn}$ status, was 78 and $46 \%$ lower in the ZD and ZMD rats, respectively, compared with the $\mathrm{ZC}$ rats.

\section{Sperm morphology and length}

ZD rats had markedly low spermatozoa integrity. More than $80 \%$ of ZD rat spermatozoa were morphologically abnormal (Fig. 1). An abnormal head was the most common abnormality in the $Z D$ rats, with an abundance of headless spermatozoa. A combined head and tail abnormality was also abundant in the ZD rats, where the head abnormality was again predominantly headless. Animals fed the ZC, ZMD and PF diet showed similar sperm morphology. The tail length of spermatozoa in the ZD rats (1361.7 (SD 109.0) $\mu \mathrm{m})$ was $24 \%$ shorter $(P<0.001)$ than the average of all other groups (1791.7 (SD 33.8) $\mu \mathrm{m})$ (Fig. 2 (B)). Pictures of spermatozoa are shown in Fig. 2 (A).

\section{Triacylglycerol and cholesterol}

The effects of $\mathrm{Zn}$ deficiency on testis TAG and cholesterol were also measured. TAG (mg/g testis) showed no significant differences between $\mathrm{Zn}$ treatment groups: ZC (0.55 (SD 0.06)); ZD (0.55 (SD 0.20)); PF (0.48 (SD 0.04)). Cholesterol (mg/g testis) was significantly $(P<0.0375)$ higher in the ZD group than in the $\mathrm{ZC}$ group while levels in the $\mathrm{PF}$ group were comparable with both the $\mathrm{ZD}$ and $\mathrm{ZC}$ animals: ZC, 0.46
(SD 0.03); ZD, 0.62 (SD 0.07); PF, 0.52 (SD 0.04). Though no significant difference, there was a trend of lower TAG:cholesterol ratio in the testes of $\mathrm{ZD}$ and $\mathrm{PF}$ animals: $\mathrm{ZC}, 1.16$ (SD 0.05); ZD, 0.90 (SD 0.29); PF, 0.92 (SD 0.01).

\section{Fatty acid composition in phospholipids}

Fatty acid composition was determined in phosphatidylcholine (PC) and phosphatidylethanolamine (PE), since these are the most abundant phospholipids in testes (Tables 2 and 3). Dietary Zn significantly altered fatty acid profile in testis phospholipids. In PC, the major long-chain PUFA found in the testes of ZC animals were $18: 2 n-6,20: 4 n-6$ and $22: 5 n-6$ at $2 \cdot 4,14 \cdot 3$ and $15 \cdot 0 \%$, respectively. Animals fed a $\mathrm{ZD}$ diet had the highest level of $18: 2 n-6$ and the lowest elongated and desaturated product of $22: 5 n-6$, while all other groups had similar levels (Table 2). Similarly, the major long-chain PUFA in ZC PE were $18: 2 n-6$, $20: 4 n-6$ and $22: 5 n-6$, at $2 \cdot 4,20 \cdot 6$ and $23.9 \%$, respectively

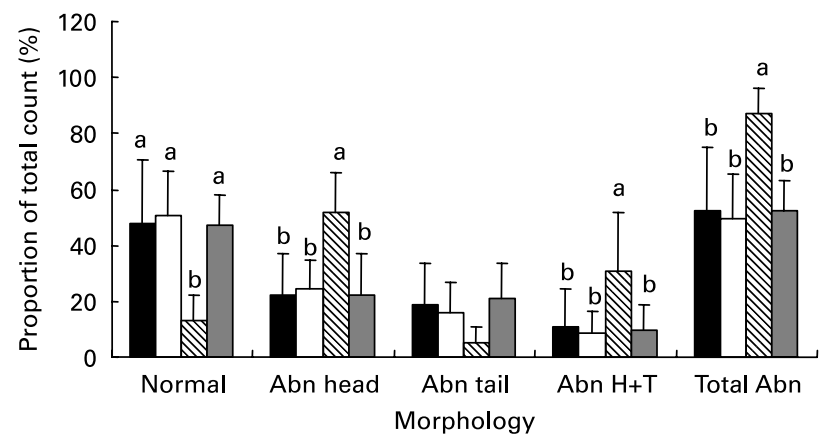

Fig. 1. Sperm morphology (\% total count) in testes in response to dietary $Z n$ treatment: $(\square)$, Zn control; $(\square)$, Zn marginally deficient; $(\mathbb{N}), \mathrm{Zn}$ deficient; $(\square)$, pair fed. Two hundred cauda epididymal spermatozoa were analysed per animal using light microscopy at a magnification of $400 \mathrm{X}$. Morphology is defined as follows: normal, hooked head and smooth tail; abnormal (Abn) head, missing head, flattened hook or pinhead; Abn tail, bent or coiled tail; Abn $\mathrm{H}+\mathrm{T}$, possessing both a head and a tail abnormality; Total Abn, sum of the three abnormality groups. Values are means $(n 5)$, with standard deviations represented by vertical bars. ${ }^{a, b}$ Within each morphology category, mean values with unlike letters were significantly different $(P<0.009)$. 
(A)
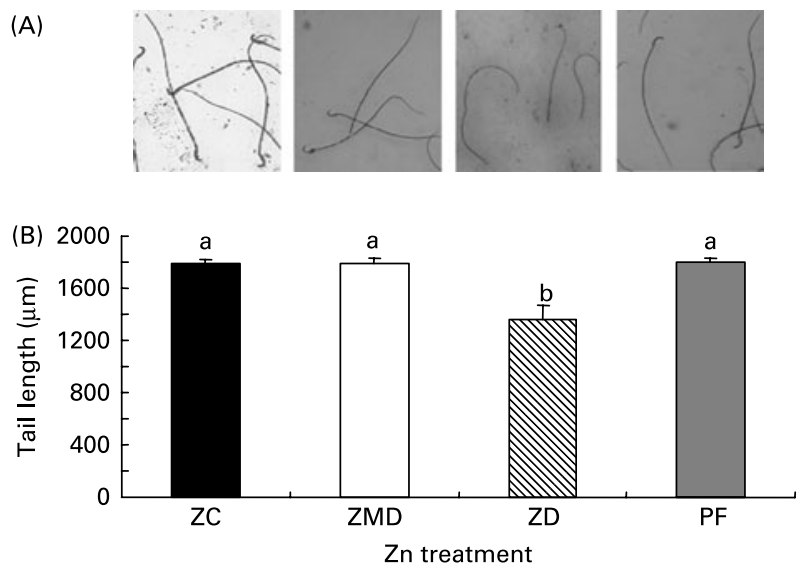

Fig. 2. Spermatozoa pictures $(A)$ and tail length $(B)$ in response to dietary $Z n$ treatment. ZC, Zn control; ZMD, Zn marginally deficient; ZD, Zn deficient; $\mathrm{PF}$, pair fed. Twenty cauda epididymal spermatozoa were analysed using Image Pro Plus 5.0 computer software (Media Cybernetics Inc., Silver Spring, MD, USA). Values are means ( $n$ 4), with standard deviations represented by vertical bars. ${ }^{a, b}$ Mean values with unlike letters were significantly different $(P<0.001)$.

(Table 3). The level of $18: 2 n-6$ in PE was highest in the rats fed a ZD diet in comparison with the other diet groups. The level of $22: 5 n-6$ was lowest in the ZD animals resulting in a higher ratio of $18: 2 n-6$ to $22: 5 n-6$ (Table 3 , Fig. 3). Although it was not statistically significant, $22: 6 n-3$ was also lowest in the ZD animals in both PC and PE. The ratio of total $n-6: n-3$ fatty acids was in the range of 25-39:1 in PC and 21-28:1 in PE, indicating a highly $n-6$ fatty acid-enriched environment in the testes ofz rats.

\section{Discussion}

The present study examined the impact of a short period of dietary $\mathrm{Zn}$ deficiency on long-chain PUFA composition in testis phospholipids and sperm integrity of growing rats.
The major fatty acid changes in PC and PE of Zn-deficient testes were elevated $18: 1$ (oleic acid) and $18: 2 n-6$, and reduced $22: 5 n-6$ compared with the other groups. These changes were only identified in animals fed a severely $\mathrm{Zn}$ deficient diet (ZD; $\leq 1 \mathrm{mg} / \mathrm{kg}$ ) for 3 weeks. The ZMD diet $(9 \mathrm{mg} \mathrm{Zn} / \mathrm{kg}$ diet) did not show the same effect. Oteiza et al. ${ }^{(22)}$ found that weanling rats on a $\mathrm{Zn}$-deficient diet $(0.5 \mathrm{mg} / \mathrm{kg}$ diet $)$ for 2 weeks had $32 \%$ lower $\mathrm{Zn}(247 \mathrm{nmol} / \mathrm{g}$ wet tissue) in the testes in comparison with control animals fed a $25 \mathrm{mg} \mathrm{Zn/kg} \mathrm{diet} \mathrm{(169} \mathrm{nmol/g} \mathrm{wet} \mathrm{tissue).} \mathrm{Since} \mathrm{our}$ feeding regimen was 3 weeks with a similar diet regimen, its level in testes could be lower. It was also evident that rat testes are highly enriched in $n-6$ long-chain PUFA, especially $22: 5 n-6$, which is normally a very minor component in other organs and tissues. Thus, the reduction of this fatty acid may overall influence testis function, spermatogenesis and androgenesis. The finding of the present study implies that the decrease of $22: 6 n-3$, enriched in human testes and sperm, could lead to abnormal sperm function. In fact, decreased $22: 6 n-3$ in the sperm phospholipid has been identified in infertile men and asthenozoospermic males ${ }^{(23,24)}$.

Testis apoptosis, before detecting any morphological changes, can be achieved at 3 weeks after initiating a diet deficient in $\mathrm{Zn}\left(<1 \mathrm{mg} \mathrm{Zn/kg} \mathrm{diet)}\right.$ in rats aged 7 weeks ${ }^{(3)}$. Furthermore, testicular atrophy with the loss of sperm cells and spermatocytes with lower relative testis weight to body weight was identified after 10 weeks. These changes depend on the severity of $\mathrm{Zn}$ deficiency ${ }^{(2,3)}$. In the present study, animals fed a ZD and a PF diet had higher relative testis weights. This implies that the testis may be the last organ to be affected by $\mathrm{Zn}$ deficiency. However, considering the sperm abnormalities found, the present study indicates that the 3-week feeding period of our diet regimen $(\leq 1 \mathrm{mg} \mathrm{Zn} / \mathrm{kg}$ ) to growing animals may also have induced apoptosis in testes. Further study is necessary to confirm the threshold of $\mathrm{Zn}$ deficiency-induced testis apoptosis regarding dietary $\mathrm{Zn}$ level, feeding period and age.

Table 2. Phosphatidylcholine fatty acid profile (\% total fatty acids) in testes in response to dietary zinc treatment (Mean values and standard deviations)

\begin{tabular}{|c|c|c|c|c|c|c|c|c|c|}
\hline \multirow{2}{*}{$\begin{array}{l}\text { Zn treatment... } \\
\text { Fatty acids }\end{array}$} & \multicolumn{2}{|c|}{ ZC† } & \multicolumn{2}{|c|}{ ZMD† } & \multicolumn{2}{|c|}{ ZD } & \multicolumn{2}{|c|}{ PF } & \multirow[b]{2}{*}{$P$} \\
\hline & Mean & SD & Mean & SD & Mean & SD & Mean & SD & \\
\hline $14: 0$ & 0.23 & 0.07 & $0 \cdot 21$ & 0.06 & 0.22 & 0.10 & 0.23 & 0.03 & NS \\
\hline $16: 0$ & 39.06 & $3 \cdot 11$ & 38.85 & $1 \cdot 27$ & 39.07 & 1.67 & $37 \cdot 10$ & $5 \cdot 34$ & NS \\
\hline $16: 1$ & 0.85 & 0.13 & 0.79 & 0.05 & 0.98 & 0.26 & $1 \cdot 10$ & 0.27 & NS \\
\hline $18: 0$ & $4 \cdot 68^{a}$ & 0.51 & $4.99^{a}$ & 0.32 & $4.49^{\mathrm{a}}$ & 0.58 & $3.79^{b}$ & 0.18 & 0.0157 \\
\hline $18: 1(9+11)$ & $15 \cdot 11^{b}$ & 1.00 & $14 \cdot 73^{b}$ & 0.53 & $17 \cdot 56^{a}$ & $1 \cdot 15$ & $15 \cdot 85^{a, b}$ & 1.54 & 0.0142 \\
\hline $18: 2 n-6$ & $4 \cdot 21^{b, c}$ & 0.97 & $3.60^{c}$ & 0.52 & $5 \cdot 96^{a}$ & $1 \cdot 14$ & $5 \cdot 08^{a, b}$ & 0.76 & 0.0127 \\
\hline $20: 3 n-6$ & $1 \cdot 30$ & 0.20 & $1 \cdot 25$ & 0.05 & 1.67 & 0.51 & 1.48 & 0.10 & NS \\
\hline $20: 4 n-6$ & $14 \cdot 25$ & $1 \cdot 32$ & $13 \cdot 25$ & 0.91 & $15 \cdot 32$ & 2.62 & $16 \cdot 00$ & 1.39 & NS \\
\hline $22: 4 n-6$ & 1.44 & 0.19 & $1 \cdot 37$ & 0.04 & $1 \cdot 22$ & 0.09 & $1 \cdot 18$ & 0.19 & NS \\
\hline $22: 5 n-6$ & $15 \cdot 24^{a}$ & $1 \cdot 13$ & $15 \cdot 52^{a}$ & 1.03 & $11 \cdot 62^{b}$ & $2 \cdot 73$ & $16 \cdot 05^{a}$ & 1.67 & 0.0158 \\
\hline $22: 6 n-3$ & $1 \cdot 26$ & 0.32 & $1 \cdot 22$ & 0.09 & 0.87 & 0.20 & $1 \cdot 32$ & 0.21 & NS \\
\hline$\Sigma$ SFA & $44 \cdot 30$ & 2.59 & 44.43 & 1.43 & $44 \cdot 16$ & 1.75 & 41.43 & $5 \cdot 18$ & NS \\
\hline$\Sigma$ MUFA & $16 \cdot 04^{b}$ & $1 \cdot 15$ & $15 \cdot 51^{b}$ & 0.52 & $18 \cdot 67^{a}$ & 0.87 & $17 \cdot 07^{b}$ & 1.59 & 0.0074 \\
\hline$\sum n-6$ & 36.56 & $2 \cdot 35$ & 35.06 & 1.08 & 35.92 & $1 \cdot 10$ & 39.93 & $3 \cdot 75$ & NS \\
\hline$\sum n-3$ & $1 \cdot 38$ & 0.37 & $1 \cdot 35$ & 0.13 & 0.92 & 0.18 & 1.35 & $0 \cdot 21$ & NS \\
\hline
\end{tabular}

ZC, Zn control; ZMD, Zn marginal deficient; ZD, Zn deficient; PF, pair fed.

a,b,c Mean values within a row with unlike superscript letters were significantly different $(P<0.05)$. 
Table 3. Phosphatidylethanolamine fatty acid profile (\% total fatty acids) in testes in response to dietary zinc treatment

(Mean values and standard deviations)

\begin{tabular}{|c|c|c|c|c|c|c|c|}
\hline \multirow{2}{*}{$\begin{array}{l}\text { Zn treatment... } \\
\text { Fatty acids }\end{array}$} & \multicolumn{2}{|c|}{ ZC† } & \multicolumn{2}{|c|}{ ZMD† } & \multirow{2}{*}{$\frac{\text { ZD }}{\text { Mean }}$} & \multirow{2}{*}{$\frac{\text { PF }}{\text { Mean }}$} & \multirow[b]{2}{*}{ Pooled SD } \\
\hline & Mean & SD & Mean & SD & & & \\
\hline $14: 0$ & 0.12 & 0.22 & 0.20 & 0.16 & 0.08 & 0.06 & 0.02 \\
\hline $16: 0$ & 23.94 & 4.56 & $17 \cdot 97^{\star}$ & 0.93 & 23.87 & 27.04 & 1.86 \\
\hline $16: 1$ & 0.35 & 0.34 & 0.31 & 0.09 & 0.31 & 0.27 & 0.03 \\
\hline $18: 0$ & 8.47 & 1.51 & $7 \cdot 14$ & 0.36 & 9.44 & 8.82 & 0.44 \\
\hline $18: 1(9+11)$ & 8.34 & 1.46 & 6.53 & 0.32 & 9.56 & $7 \cdot 67$ & $1 \cdot 15$ \\
\hline $18: 2 n-6$ & 2.38 & 0.39 & $2 \cdot 26$ & 0.23 & $3 \cdot 82$ & 3.12 & $1 \cdot 15$ \\
\hline $20: 3 n-6$ & 0.63 & 0.05 & 0.63 & 0.07 & 0.74 & 0.71 & 0.07 \\
\hline $20: 4 n-6$ & $20 \cdot 60$ & 2.49 & $17 \cdot 83$ & 1.88 & 22.19 & 18.43 & $2 \cdot 75$ \\
\hline $22: 4 n-6$ & 3.44 & 0.55 & 3.57 & 0.11 & 3.88 & 3.48 & 0.46 \\
\hline $22: 5 n-6$ & 23.94 & $2 \cdot 23$ & 24.66 & 1.47 & $22 \cdot 88$ & $26 \cdot 65$ & 2.54 \\
\hline $22: 6 n-3$ & 2.01 & 0.48 & 2.08 & 0.14 & 1.85 & $2 \cdot 37$ & 0.52 \\
\hline$\Sigma$ SFA & 33.65 & 6.06 & $25 \cdot 68^{*}$ & 1.09 & 34.40 & 36.92 & 1.52 \\
\hline$\Sigma$ MUFA & 9.45 & 1.76 & $9 \cdot 17$ & 0.98 & $10 \cdot 04$ & 8.07 & $1 \cdot 19$ \\
\hline$\sum n-6$ & 51.04 & 3.05 & 48.97 & $1 \cdot 17$ & 53.55 & 52.44 & 0.85 \\
\hline$\sum n-3$ & $2 \cdot 19$ & 0.68 & $2 \cdot 33$ & 0.17 & 1.89 & $2 \cdot 39$ & 0.51 \\
\hline
\end{tabular}

ZC, Zn control; ZMD, Zn marginal deficient; ZD, Zn deficient; PF, pair fed.

${ }^{*}$ Mean value was significantly different from that of the $Z C$ group $(P<0 \cdot 05)$.

$\dagger n 3$ per group.

$\ddagger n$ 2, therefore pooled SD is presented. Trend analysis $\left(R^{2}\right)$ was performed on the two independent datasets $\left(R^{2} 0.9957\right.$ and 0.9963 , in the ZD and PF groups, respectively).

The present study demonstrated that spermatozoa integrity is adversely affected with a Zn-deficient diet. Stoltenberg et al. ${ }^{(25)}$ have demonstrated in vitro that $\mathrm{Zn}$ distribution in the spermatozoa varies depending on its stage of maturation within the epididymis. Once formed in the testis seminiferous tubules, immature spermatozoa migrate to the caput of the epididymis, when $\mathrm{Zn}$ is mostly concentrated in the tail. Spermatozoa then mature and gain mobility as they continue through the epididymal duct to the cauda epididymis, in which $\mathrm{Zn}$ is highly and almost uniquely concentrated in the acrosome of the head. Our findings reveal that spermatozoa head and combined head and tail abnormalities are the most frequent abnormalities and tail length is stunted in $\mathrm{Zn}$ deficiency. This indicates that $\mathrm{Zn}$ is involved in not only promoting the maturation of testis germinal cells into spermatozoa ${ }^{(1,2)}$ but also in epididymal sperm maturation.

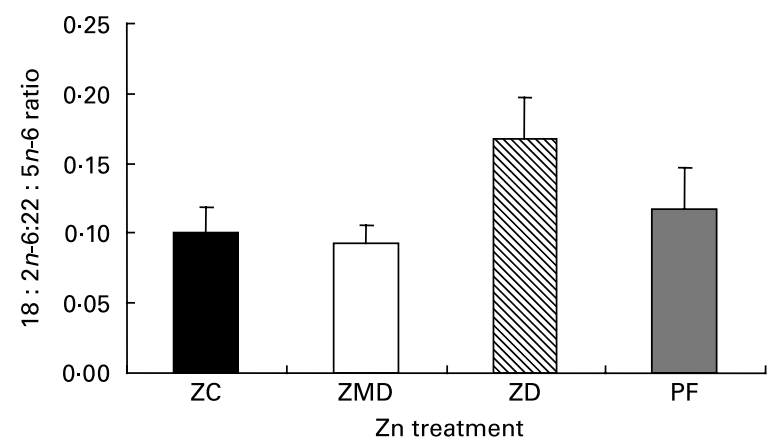

Fig. 3. Effect of $Z n$ treatment on the ratio of $18: 2$ to $22: 5 n-6$ in testis phosphatidylethanolamine. ZC, Zn control; ZMD, Zn marginally deficient; ZD, Zn deficient; PF, pair fed. For ZC and ZMD, values are means $(n 3)$, with standard deviations represented by vertical bars. For ZD and PF, because the data represent $n 2$, values are means, with pooled standard deviations.
The present study showed that essential fatty acid metabolism is interrupted by $\mathrm{Zn}$ deficiency in testes. Specifically, there is an interruption in the $n-6$ essential fatty acid desaturation and elongation from $18: 2 n-6$ to $22: 5 n-6$ when $\mathrm{Zn}$ is severely but not marginally deficient. Cunnane et al. ${ }^{(11)}$ also found high levels of $18: 2 n-6$ with a decrease of $20: 4 n-6$ in testes of $\mathrm{Zn}$-deficient rats. The present study showed a decrease in $22: 5 n-6$, a major fatty acid in testes. In consideration of precursors and metabolites in essential fatty acid metabolism, the ratios of $18: 2 n-6: 20: 4 n-6,18: 2 n-6: 22: 4 n-6$ and $18: 2 n-6: 22: 5 n-6$ were all higher in the ZD group than the other diet groups (Fig. 4). These data confirm the effects of inhibited activity of the $\Delta 6$ and $\Delta 5$ desaturases as put forth by Ayala \& Brenner ${ }^{(10)}$. However, the existence of two different $\Delta 6$ desaturases has been proposed for the synthesis of long-chain PUFA ${ }^{(26)}$, one in microsomes and the other in peroxisomes. Whether both desaturases are affected by $\mathrm{Zn}$ deficiency requires further investigation. Although the specific function of $22: 5 n-6$ is not well known, the present results indicate that the reduction of this fatty acid could be one of the mechanisms for $\mathrm{Zn}$ deficiency-induced inhibited spermatogenesis or testis atrophy. In addition, longchain PUFA are membrane-associated fatty acids rather than used as substrates for oxidation or energy production, thus the low level of $22: 5 n-6$ may affect the membrane integrity in both testes and spermatozoa. In another study conducted in our laboratory, we have found underdeveloped rat testes to have a uniquely low concentration of $22: 5 n-6$ that is not shared with normal-sized testes (M. Suh, unpublished results).

Whether supplementation of 22:5n-6 reverses Zn deficiencyrelated defects in sperm development is not known. Chanmugam et al. ${ }^{(27)}$ supplemented Zn-deficient rats with $22: 5 n-6(0.58 \%$, $\mathrm{w} / \mathrm{w}$ of total fatty acids) in a $10 \%$ fat-containing diet for 6 weeks. This study found that there were no changes in the level of $22: 5 n-6$ in the testis phospholipids of the $\mathrm{Zn}$-deficient rats. The supplementation of $22: 5 n-6$ did not alter the body 
(A)

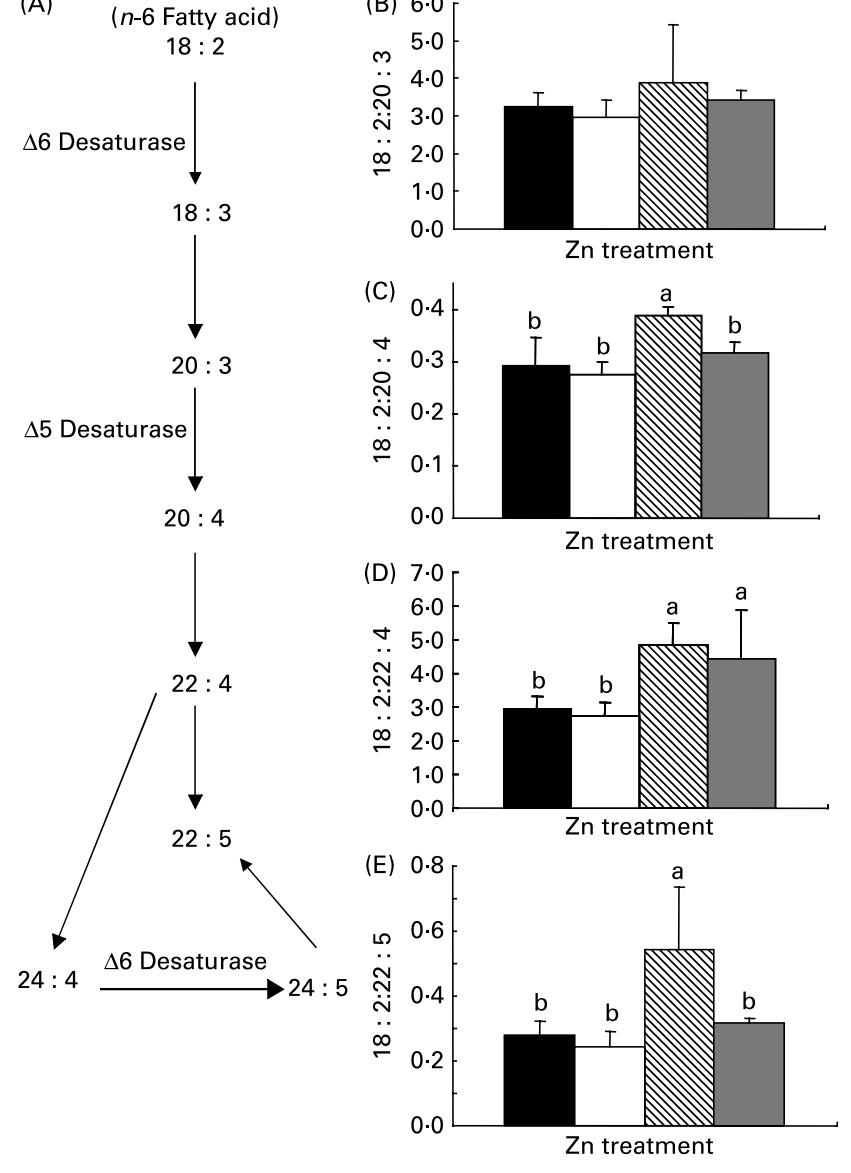

Fig. 4. Effect of $\mathrm{Zn}$ treatment on desaturation and elongation of $n-6$ fatty acids in testis phosphatidylcholine. (A) Desaturation and elongation metabolic pathway, showing Sprecher's pathway ${ }^{(28)}$. (B) 18:2:20:3 precursor:product ratio; (C) 18:2:20:4 precursor:product ratio; (D) 18:2:22:4 precursor:product ratio; (E) 18:2:22:5 precursor:product ratio. ( $\square$ ), $\mathrm{Zn}$ control $(n$ 5); $(\square)$, Zn marginally deficient ( $n 5)$; ( $\mathbb{\$})$, Zn deficient $(n 3)$; $(\square)$, pair fed $(n 3)$. Values are means, with standard deviations represented by vertical bars. ${ }^{\mathrm{a}, \mathrm{b}}$ Mean values with unlike letters were significantly different $(P<0.04)$.

weight, plasma Zn, liver weight, testis weight and spermatid number. But $22: 5 n-6$ increased the level of testis $\mathrm{Zn}$ with no clear explanation. This indicates that when $\mathrm{Zn}$ deficiency is established, providing $22: 5 n-6$ does not reverse the effect induced by $\mathrm{Zn}$ deficiency. It will be of interest to see the level of $22: 5 n-6$ if the $\mathrm{Zn}$-deficient animals are re-supplemented. Overall, this study confirms our findings that $\mathrm{Zn}$ deficiency interrupts essential lipid metabolism or incorporation of fatty acids to testes.

The present study demonstrates that dietary $\mathrm{Zn}$ deficiency during sexual maturation alters testis fatty acid composition in rats and affects sperm integrity. These results suggest that $\mathrm{Zn}$ deficiency-associated abnormal testicular function is perhaps preceded by alterations in membrane fatty acid composition, especially $22: 5 n-6$ in rats. Further studies are necessary to determine which stages of sperm cell spermatogenesis are affected by dietary $\mathrm{Zn}$ or $\mathrm{Zn}$ status.

\section{Acknowledgements}

The present study was supported by a grant from the Natural Science and Engineering Research Council of Canada. The authors would like to thank Ms Lisa Maximiuk and Mr Dennis Labossiere for collecting tissues and technical assistance.

There is no conflict of interest to declare by any of the authors.

\section{References}

1. Bedwal RS \& Bahuguna A (1994) Zinc, copper and selenium in reproduction. Experientia 50, 626-640.

2. El Hendy HA, Yousef MI \& Abo El-Naga NI (2001) Effect of dietary zinc deficiency on hematological and biochemical parameters and concentrations of zinc, copper, and iron in growing rats. Toxicology 167, 163-170.

3. Nodera M, Yanagisawa H \& Wada O (2001) Increased apoptosis in a variety of tissues of zinc-deficient rats. Life Sci $\mathbf{6 9}$, 1639-1649.

4. Hamdi SA, Nassif OI \& Ardawi MS (1997) Effect of marginal or severe dietary zinc deficiency on testicular development and functions of the rat. Arch Androl 38, 243-243.

5. Li J, Xu P \& He Z (1998) Effect of zinc deficiency on apoptosis of spermatogenic cells of rat testis. Zhonghua Yi Xue Za Zhi 78, 91-93.

6. Abbasi AA, Prasad AS, Rabbani P, et al. (1980) Experimental zinc deficiency in man. Effect on testicular function. $J \mathrm{Lab}$ Clin Med 96, 544-550.

7. Robinson BS, Johnson DW \& Poulos A (1992) Novel molecular species of sphingomyelin containing 2-hydroxylated polyenoic very-long-chain fatty acids in mammalian testes and spermatozoa. J Biol Chem 267, 1746-1751.

8. Retterstøl K, Haugen TB, Tran TN, et al. (2001) Studies on the metabolism of essential fatty acids in isolated human testicular cells. Reproduction 121, 881-887.

9. Clejan S, Castro-Magana M, Collipp PJ, et al. (1982) Effects of zinc deficiency and castration on fatty acid composition and desaturation in rats. Lipids 17, 129-135.

10. Ayala S \& Brenner RR (1983) Essential fatty acid status in zinc deficiency. Effect on lipid and fatty acid composition, desaturation activity and structure of microsomal membranes of rat liver and testes. Acta Physiol Lat Am 33, 193-204.

11. Cunnane SC, Horrobin DF \& Manku MS (1984) Essential fatty acids in tissue phospholipids and triglycerides of the zincdeficient rat. Proc Soc Exp Biol Med 177, 441-446.

12. Clejan S, Maddaiah VT, Castro-Magana M, et al. (1981) Zinc deficiency-induced changes in the composition of microsomal membranes and in the enzymatic regulation of glycerolipid synthesis. Lipids 16, 454-460.

13. Lepage LM, Giesbrecht JC \& Taylor CG (1999) Expression of $\mathrm{T}$ lymphocyte $\mathrm{p} 56^{\mathrm{lck}}$, a zinc-finger signal transduction protein, is elevated by dietary zinc deficiency and diet restriction in mice. J Nutr 129, 620-627.

14. Olfert ED, Cross BM \& McWilliam AA (1993) Guide to the Care and Use of Experimental Animals, vol. 1,2, 2nd ed. Ottawa: Canadian Council on Animal Care.

15. Hosea HJ, Taylor CG, Wood T, et al. (2004) Zinc-deficient rats have more limited bone recovery during repletion than dietrestricted rats. Exp Biol Med 229, 303-311.

16. Sprando RL, Collins TFX, Black TN, et al. (1999) Light microscopic observations on the reproductive tract of the male sand rat, Psammomys obesus. Tissue Cell 31, 99-115.

17. Industrial Reproductive Toxicology Discussion Group (IRDG) and Computer Assisted Sperm Analysis (CASA) Group (2000) Rat Sperm Morphological Assessment Guideline Document, 1st ed. http://www.irdg.co.uk/Sperm_morphology.pdf

18. Folch J, Lees M \& Sloane Stanley GH (1957) A simple method for isolation and purification of total lipides from animal tissues. J Biol Chem 226, 497-509. 
19. Suh M, Wierzbicki AA \& Clandinin MT (1994) Dietary fat alters membrane composition in rod outer segments in normal and diabetic rats: impact on content of very-long-chain $(C \geq 24)$ polyenoic fatty acids. Biochim Biophys Acta 1214, 54-62.

20. Park EJ, Suh M, Ramanujam K, et al. (2005) Diet-induced changes in membrane gangliosides in rat intestinal mucosa, plasma and brain. J Pediatr Gastroenterol Nutr 40, 487-495.

21. Steel RGD \& Torrie JH (1990) Principals and Procedures of Statistics, 2nd ed., chapters 8 and 9. New York: McGraw-Hill.

22. Oteiza PI, Olin KL, Fraga CG, et al. (1995) Zinc deficiency causes oxidative damage to proteins, lipids and DNA in rat testes. J Nutr 125, 823-829.

23. Zalata AA, Christophe AB, Depuydt CE, et al. (1998) The fatty acid composition of phospholipids of spermatozoa from infertile patients. Mol Hum Reprod 4, 111-118.

24. Tavilani H, Doosti M, Nourmohammadi I, et al. (2007) Lipid composition of spermatozoa in normozoospermic and asthenozoospermic males. Prostaglandins Leukot Essent Fatty Acids 77, 45-50.

25. Stoltenberg M, Sørenson MB, Danscher G, et al. (1997) Autometallographic demonstration of zinc ions in rat sperm cells. Mol Hum Reprod 3, 763-767.

26. Marzo I, Alava MA, Oineiro A, et al. (1996) Biosynthesis of docosahexaenoic acid in human cells: evidence that two different $\Delta 6$-desaturase activities may exist. Biochim Biophys Acta 1301, 263-272.

27. Chanmugam P, Wheeler C \& Hwang DH (1984) Fatty acid composition of the testes of zinc-deficient rats: the effect of docosapentaenoic acid supplementation. J Nutr 114, 2073-2079.

28. Voss A, Reinhart M, Sankarappa S, et al. (1991) The metabolism of 7, 10, 13, 16, 19-docosapentaenoic acid to 4, 7, 10, 13, 16, 19-docosahexaenoic acid in rat liver is independent of a 4-desaturase. J Biol Chem 266, 1995-2000. 